\title{
A centennial-resolution terrestrial climatostratigraphy and Matuyama- Brunhes transition record from a loess sequence in China
}

\author{
Masayuki Hyodo ${ }^{1,2^{*}}$ (D) Kenta Banjo ${ }^{2}$, Tianshui Yang ${ }^{3}$, Shigehiro Katoh ${ }^{4}$, Meinan Shi ${ }^{5}$, Yuki Yasuda ${ }^{1,6}$, \\ Jun-ichi Fukuda ${ }^{1,2}$, Masako Miki ${ }^{2}$ and Balázs Bradák ${ }^{7}$
}

\begin{abstract}
Terrestrial records of the last geomagnetic reversal often have few age constraints. Chronostratigraphy using suborbital-scale paleoceanic events during marine isotope stage 19 may contribute to solving this problem. We applied the method to an $8 \mathrm{~m}$ long, high-resolution paleomagnetic record from a loess sequence in China and revealed millennial-to-sub-centennial scale features of the Matuyama-Brunhes (MB) transition. All samples were subjected to progressive thermal demagnetization with $14-15$ steps up to $650-680{ }^{\circ} \mathrm{C}$. As a result, $96 \%$ of the samples yielded a high-quality remanent magnetization. The MB transition terminated with a $75 \mathrm{~cm}$ thick zone with nine polarity flips. The polarity flip zone, dated at about 779-777 ka, began between the warm events "I" and "J" and terminated at the end of the cooling event coincident with the lowest axial-dipole strength interval. Most polarity flips occurred within 70 years. The virtual geomagnetic poles (VGPs) in the upper polarity flip zone clustered in the SW Pacific region, where the MB transitional VGPs from lavas of the Hawaiian and Canary Islands and lacustrine deposits of Java also clustered. These sites were probably dominated by dipolar fields. The absence of transitional fields across polarity flips implies a short time span for averaging fields due to a thin loessmagnetization lock-in zone. The reverse-to-normal polarity reversal dated at about $778 \mathrm{ka}$ in Lingtai occurred at the end of the SW Pacific VGP zone, an important key bed for MB transition stratigraphy. The reversal is a good candidate for the main MB boundary. We found an excursion at about 766 ka spanning about $1 \mathrm{ka}$.
\end{abstract}

Keywords: Loess-paleosol, Geomagnetic reversal, Early-Middle Pleistocene transition, Loess magnetism, East Asian monsoon

\section{Introduction}

Pleistocene marine and terrestrial sequences can provide continuous records of geomagnetic field variations as well as climate changes, on various time scales. Therefore, these records are useful for constructing "magnetoclimatostratigraphy," a hybrid stratigraphy that enables more precise stratigraphic correlations on global scales.

\footnotetext{
* Correspondence: mhyodo@kobe-u.ac.jp

${ }^{1}$ Research Center for Inland Seas, Kobe University, Kobe 657-8501, Japan

${ }^{2}$ Department of Planetology, Kobe University, Kobe 657-8501, Japan

Full list of author information is available at the end of the article
}

For the marine isotope stage (MIS) 19 interglacial period, decadal-to-centennial-resolution paleoceanic and paleoclimate variation records have been obtained from marine sediments (Kitaba et al. 2009, 2013, 2017; Ferretti et al. 2015; Maegakiuch et al. 2016; Hyodo et al. 2017), from which a number of centennial-to-millennial scale climate events have been found (Hyodo et al. 2017). In addition, many high-resolution Matuyama-Brunhes (MB) magnetic polarity transition records from various regions have revealed submillennial-scale features of geomagnetic field changes (e.g., Wang et al. 2006; Hyodo 
et al. 2006, 2011; Channell et al. 2010; Okada et al. 2017). However, the detailed geomagnetic records have never been analyzed together with the centennial-scale climate changes. This may partly be a result of the lockin of magnetization of sediments being incompletely understood (e.g., Hyodo 1984; deMenocal et al. 1990; Suganuma et al. 2010).

Loess-paleosol sequences in the Chinese Loess Plateau (CLP) are excellent archives of geomagnetic field variations because loess-paleosol layers have stable remanent magnetizations (e.g., Zhu et al. 1994; Yang et al. 2004, 2007,2008 ). In addition, orbital-scale correlation of loess and paleosol units with marine oxygen isotope stages (MISs) has almost been established (Kukla 1987; Sun et al. 2006). Each paleosol layer is numbered and correlated, such as paleosol S0 (MIS 1), S1 (MIS 5), and S2 (MIS 7). Furthermore, the Dansgaard-Oeschger and Bond events recorded in loess-paleosol sequences (Porter and An 1995; Wang et al. 2005) may enable the construction of even millennial-scale climatostratigraphy.

The MB magnetic polarity transition, the last geomagnetic reversal, has been investigated often using loesspaleosol sequences (e.g., Spassov et al. 2001; Liu et al. 2008; Jin and Liu 2011; Yang et al. 2010). Many highresolution loess records of the transition are characterized by multiple, rapid polarity flips (Wang et al. 2006; Yang et al. 2010; Spassov et al. 2001). However, the sequential polarity flips have seldom been correlated between distant sites (Yang et al. 2010). The different numbers of flips in each record may be one of the reasons. Therefore, the question of whether the rapid polarity flips are even real geomagnetic phenomena has been discussed (Jin and Liu 2010). Nonetheless, the multiplepolarity flips during the $\mathrm{MB}$ transition are also evidenced by terrestrial sequences of lava flows (Coe et al. 2004; Singer et al. 2005) and marine and lacustrine sediments (e.g., Channell and Kleiven 2000; Channell et al. 2010; Hyodo et al. 2006, 2011). Another unresolved problem is that there are different climatostratigraphic interpretations for the MB transition, which lies in the upper part of the S8 paleosol layer. The $\mathrm{S} 8$ paleosol layer is mainly correlated in two ways: to MIS 21 (Ding et al. 2002; Sun et al. 2006; Hao et al. 2012) and to MIS 19 (Liu et al. 2008; Wang et al. 2006; Ueno et al. 2019). The different correlations are strongly related to the lock-in depths of magnetization of the loess. These problems of loess-paleosols may be resolved by combination with high-resolution climatostratigraphy.

In this study, a high-resolution and high-quality paleomagnetic record was obtained from an $8 \mathrm{~m}$ thick loess-paleosol sequence in Lingtai, central CLP. We evaluated the timing and millennial-to-centennial scale behaviors of the MB transition in combination with the published centennial-resolution paleoclimate record from the same section (Ueno et al. 2019).

\section{Methods/Experimental}

Oriented block samples (each $15-20 \mathrm{~cm}$ high) were collected from a $7.8 \mathrm{~m}$ section covering the stratigraphy of the loess L9, paleosol S8, loess L8, and paleosol S7 layers (in ascending order). In the laboratory, each block was cut into cubes, $2.2 \mathrm{~cm}$ on each side, using a knife and then dressed into $2 \times 2 \times 2 \mathrm{~cm}^{3}$ specimens using sandpaper. Specimens were collected at $2.5 \mathrm{~cm}$ depth intervals around the magnetic polarity transition interval and at 6 $\mathrm{cm}$ depth intervals on average throughout the section. In total, 130 specimens were taken for paleomagnetic measurements, and 61 specimens were taken for rock magnetic experiments.

All specimens were subjected to progressive thermal demagnetization (THD) at intervals of $30-50^{\circ} \mathrm{C}$ up to $680^{\circ} \mathrm{C}$. Natural remanent magnetization (NRM) of specimens was measured using a $2 \mathrm{G}$ cryogenic magnetometer. Low-field magnetic susceptibility $(\chi)$ was measured using a magnetic susceptibility meter (SM-100, ZH Instruments, Brno, Czech Republic). The anisotropy of low-field magnetic susceptibility (AMS) was measured using a KLY-3S Kappabridge susceptometer (AGICO, Brno, Czech Republic). Anhysteretic remanent magnetization (ARM) was imparted with a peak alternating field of $100 \mathrm{mT}$ superimposed on a direct current biased field of $50 \mu \mathrm{T}$.

We performed thermomagnetic analyses in an air atmosphere on selected samples using an NMB-89 magnetic balance (Natsuhara Giken Corporation, Osaka, Japan). A sample was heated from 50 to $700^{\circ} \mathrm{C}$ and then cooled to $50^{\circ} \mathrm{C}$ at a rate of $10^{\circ} \mathrm{C} / \mathrm{min}$. Isothermal remanent magnetization (IRM) acquisition, hysteresis experiments, and first-order reversal curve (FORC) measurements (Pike et al. 1999; Roberts et al. 2000) were performed for selected bulk loess and paleosol samples using a VSM MicroMag 3900 (Princeton Measurements Corporation, Westerville, $\mathrm{OH}, \mathrm{USA})$. The IRM was measured at 100 levels from 0.1 to $1000 \mathrm{mT}$, and the data were analyzed using IRMUNMIX 2.2 software (Heslop et al. 2002). FORC distributions were processed using FORCinel 1.18 software (Harrison and Feinberg 2008) with a smoothing factor of 3-5.

\section{Results}

\section{Thermomagnetic analysis, IRM spectra, and AMS}

Representative thermomagnetic $(J-T)$ curves for samples from loess and paleosol layers (Fig. 1a, b) and the transition zone (Fig. 1c, d) exhibit the same features. All samples show magnetization reductions at approximately 580 and $680^{\circ} \mathrm{C}$, indicating the presence of magnetite and hematite, respectively. In addition, the inflections in the heating curves at around $300{ }^{\circ} \mathrm{C}$ and the absence of corresponding signals in the cooling curves imply the presence of maghemite. The first derivatives of the heating curves (Fig. 1a-d) show that maghemite decomposes mainly between 240 and $340{ }^{\circ} \mathrm{C}$; it is then oxidized to 





form hematite. The loess and paleosols contain coarse, detrital magnetite particles with ultrathin maghemite shells formed by low-temperature oxidation in the surrounding air (van Velzen and Dekkers 1999; Liu et al. 2003, 2004). The inflection in the paleosol sample heating curve at around $300^{\circ} \mathrm{C}$ is smaller than that in the loess sample heating curve, which is more clearly seen in the first derivatives of the heating curves (Fig. 1a, b). Thus, the relative content of maghemite in the paleosol is much smaller than that in the loess.

The $J-T$ curves show clear reductions in sample magnetization after heating-cooling treatments, which reflect the high-temperature oxidation of maghemite and fine-grained magnetite to form weakly magnetic hematite. The reductions range from 27 to $46 \%$ (Fig. 1). The reduction levels depend on the $X$ values of the samples, as the smallest $\chi$ sample (nearly pristine loess) had the largest reduction, and the largest $X$ sample (mature paleosol) had the smallest reduction (Fig. 1e). Similar $X$ dependence is observed in the reduction component of maghemite decomposition estimated using the first derivatives of the $J-T$ heating curves (Fig. 1f). These results imply that pedogenic fine-grained magnetites, which must be dominant in paleosols, contributed little to the reduction. It is plausible that the reduction was attributable mainly to thermal oxidation of fine-grained detrital magnetites and thermal decomposition of maghemites, most of which were present as shells around coarse detrital magnetite grains. The present results indicate a near absence of pedogenic maghemites, consistent with previous studies that showed that most of the maghemite in the paleosol samples is detrital (Spassov et al. 2003; Maher 2016; Hyodo et al. 2020). Therefore, the superfine (single-domain (SD)/superparamagnetic (SP)) ferrimagnets that must be contained in the mature paleosols probably underwent neither maghemitization nor thermal oxidation. This inference is consistent with the TEM observation that pedogenic magnetites formed authigenically within phyllosilicate grains, such that silicates protect the authigenic magnetites from oxidation (Hyodo et al. 2020).

The IRM was unmixed into three components with gradient maxima of approximately 30,100 , and $>\sim 200$ $\mathrm{mT}$ of $\mathrm{B}_{1 / 2}$ for both the loess and paleosol bulk samples (Fig. $1 \mathrm{~g}, \mathrm{~h}$ ). The only difference between the loess and paleosol samples was their relative contributions. The low $\mathrm{B}_{1 / 2}$ component $(\sim 30 \mathrm{mT})$ was predominant in the paleosol samples, whereas the medium $B_{1 / 2}$ component $(\sim 100 \mathrm{mT})$ was predominant in the loess samples. The high $\mathrm{B}_{1 / 2}$ component $(>\sim 200 \mathrm{mT}$ ) was moderately represented in both the loess and paleosol samples. The Bcr of SD-pseudo-single-domain (PSD)-sized intergrown magnetites ranges from approximately 20 to 50 $\mathrm{mT}$ (Heider et al. 1996). Considering the magnetic carriers estimated from the thermomagnetic analyses, the low $\mathrm{B}_{1 / 2}$ component must be dominated by pedogenic magnetites. The high $\mathrm{B}_{1 / 2}$ component comprises detrital and pedogenic hematites, based on the TEM observations that revealed the presence of interlayer authigenic hematite particles within phyllosilicate grains (muscovite and chlorite), in addition to discrete detrital hematite particles between silicate grains (Hyodo et al. 2020). The medium $B_{1 / 2}$ component comprises coarse detrital magnetites with maghemite rims. The higher $B_{1 / 2}$ values $(\sim 100 \mathrm{mT})$ for the coarse magnetites would be caused by the maghemite rim, which increases the coercivity of magnetite particles due to the enhanced stress induced by the oxidation gradient between the maghematized rim and the magnetite core (van Velzen and Zijderveld 1995). The correlation of the magnetic minerals based on the $J-T$ curves with the IRM components in this study is consistent with the correlation based on the same experiments using many more samples from different regions (Hyodo et al. 2020).

The AMS data show that the maximum axes represent nearly horizontal directions and that the minimum axes represent vertical ones (Fig. 1i). Therefore, the loesspaleosol sequence underwent little disturbance of sediment structure. If they formed on silicate surfaces or between silicate grains, the crystal growth directions of pedogenic magnetic particles would be independent of the depositional plane. The observed horizontal maximum axes (Fig. 1i) indicate that pedogenic magnetites consist mainly of authigenic ones grown along layers of phyllosilicates deposited horizontally.

\section{Hysteresis loops and FORC diagrams}

The hysteresis loops of samples with different magnetic susceptibilities show slight differences in magnetic coercivity (Hc) and loop shape (Fig. 2) between loess and paleosol samples. The higher Hc of the loess samples, dominated by detrital magnetic particles (Fig. 2a), would be caused mainly by detrital magnetites with a maghemite shell. The slightly "wasp-waisted" shape of the loop for the paleosol samples, dominated by pedogenic magnetic particles (Fig. 2b, c), may be caused by a mixture of two magnetic components with strongly contrasting coercivities (Roberts et al. 1995). The two components are probably pedogenic magnetites and hematites. The FORC diagrams of both the loess and paleosol samples show a peak at $<20 \mathrm{mT}$, which indicates a dominance of SD particles, and also show modestly divergent distributions at low coercivities, which indicates the presence of vortex-state particles (Fig. 2). The slightly higher coercivity and broader vertical spread for the loess sample is probably the effect of coarse detrital magnetites with a maghemite shell. In contrast, the lower coercivity and similar FORCs (Fig. 2b, c) of the paleosol reflect the 


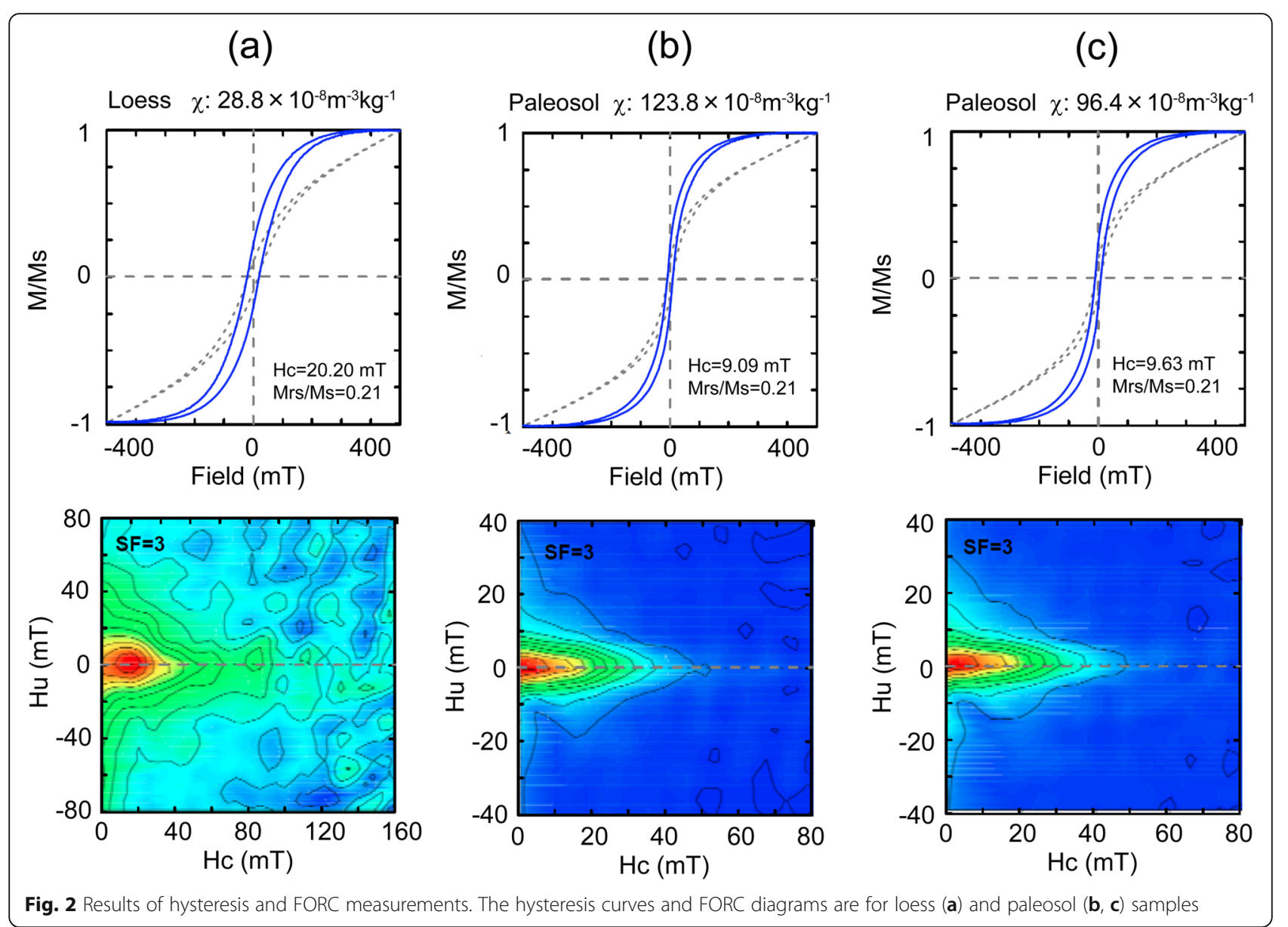

dominance of pedogenic magnetites. The asymmetrical diverging contours lying close to the origin in all FORCs are likely due to SP particles (Pike et al. 2001; Roberts et al. 2000).

\section{Progressive thermal demagnetization}

As shown by the typical results of progressive THD (Fig. 3a, b), most of the samples have NRMs that show quite linear vectorial decay toward the origin with temperatures ranging from $200-300$ to $620-680^{\circ} \mathrm{C}$. The range of temperature implies that the NRM is carried by magnetite and hematite, and each mineral component has the same direction. Such NRM data were obtained from about $70 \%$ of the samples, all collected from the full-normal or full-reverse polarity zones, independent of the $X$ or the degree of pedogenesis. The remaining samples mostly had a single NRM component with a temperature range from $200-300$ to $530-590^{\circ} \mathrm{C}$ carried by magnetite (Fig. 3c, d). These samples had no isolatable higher-temperature $\left(>590^{\circ} \mathrm{C}\right)$ component carried by hematite. Several samples had multi-component NRMs (Fig. 3e-i) with weak intensity. These samples were all from a magnetic polarity flip zone and just above it. Five samples had a quite low-intensity NRM that showed no linear decay of the magnetic vector. These samples were also from the magnetic polarity flip zone, or just below it.

\section{Paleomagnetic directions}

Characteristic remanent magnetization (ChRM) directions were determined by principle component analysis using the THD data of 125 samples, 2 of which were from the same depth $(197 \mathrm{~cm})$. Some of the results are listed in Table 1. The average number of demagnetization steps of the data used for the analysis was 10.4, and the mean maximum angular deviation (MAD) (Kirschvink 1980) was 3.6. Most of the ChRMs were carried by magnetite (Fig. 3a-d). Of the 125 samples, 4 had another component carried mainly by hematite (Fig. 3e-h). The two components had relatively close directions (Fig. 3f-h), except for the sample at 337 $\mathrm{cm}$, which had magnetite-carrying normal-polarity and hematite-carrying reverse-polarity components (Fig. 3e). The sample was located at a depth underlain by a short reverse-polarity episode and overlain by a normal-polarity succession (Table 1). From this situation, the reversepolarity hematite-carrying component was probably acquired first, followed by acquisition of the normal-polarity magnetite-carrying component. This delay in acquisition 
(a)

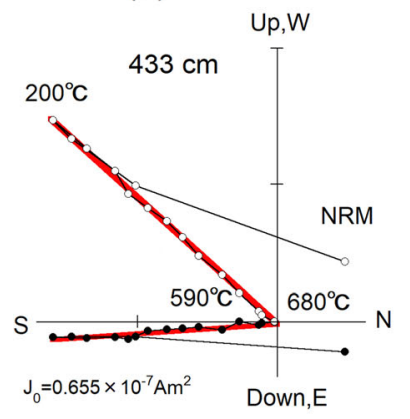

(d)

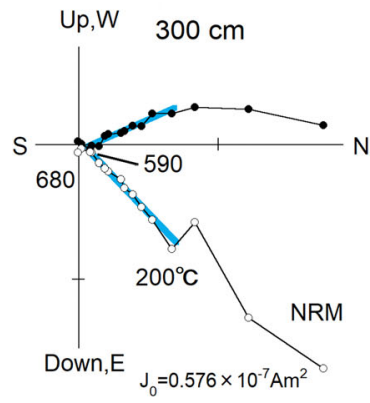

(g)

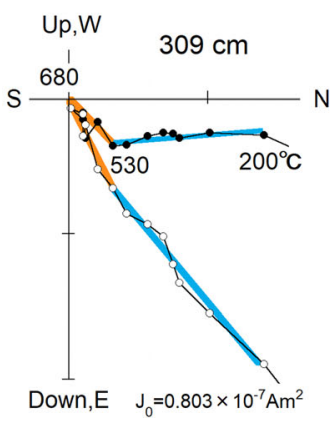

(b)

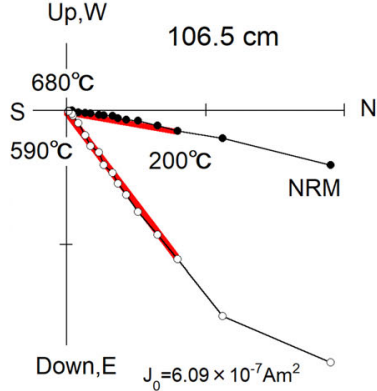

(e)

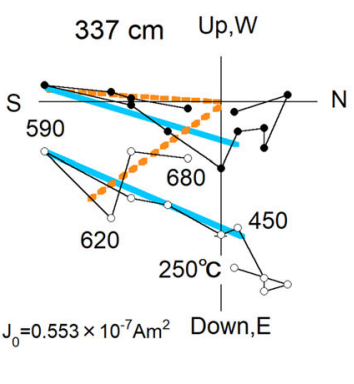

(h)

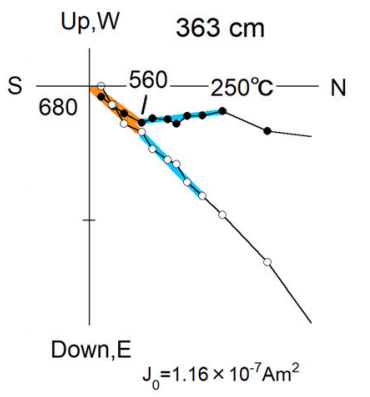

(c)

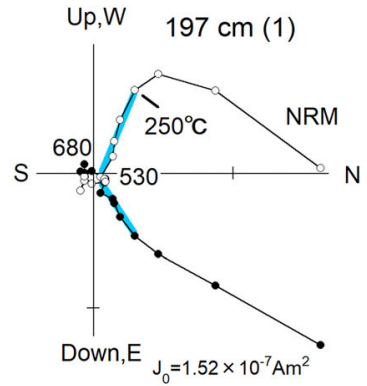

(f)

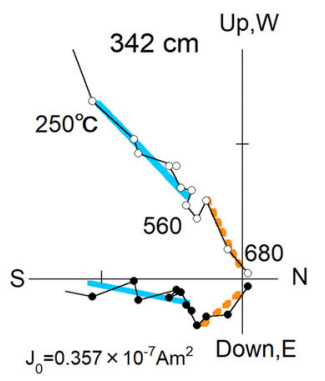

(i)

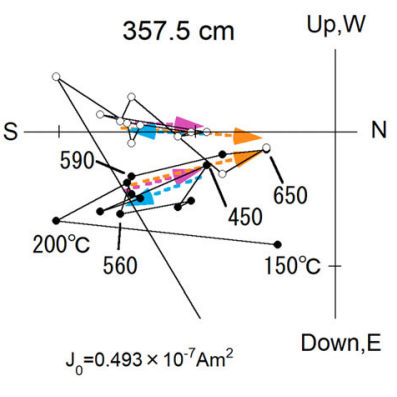

Fig. 3 Vector end-point diagrams. The solid/open circles show projections on the horizontal/vertical planes, respectively. Red lines in $\mathbf{a}, \mathbf{b}$ show single normal/reverse components obtained from most of samples. In $\mathbf{c}$ to $\mathbf{h}$, blue/orange lines show magnetite-/hematite-carried components, respectively. i Pink/blue/orange arrows show low/middle/high-temperature components, respectively

would reflect the time to the adjacent sample $(5 \mathrm{~cm}$ distance in this case). The former should be the result of detrital remanent magnetization (DRM), and the latter should be the result of pedogenic remanent magnetization (PRM). The sample at $357.5 \mathrm{~cm}$ comprised three components with temperature ranges of $250-450{ }^{\circ} \mathrm{C}$ (low), $450-560^{\circ} \mathrm{C}$ (middle), and $560-650^{\circ} \mathrm{C}$ (high) (Fig. 3i). The low/middle- and high-temperature components would be carried mainly by magnetite and hematite, respectively. The low-temperature magnetitecarrying component and the hematite-carrying component had similar low-inclination reverse-polarity directions, which probably indicate DRM. On the other hand, the middle-temperature magnetite-carrying component had a low-inclination normal-polarity direction, which probably indicates PRM (Fig. 3i). The depth of the three-component sample was $2.5 \mathrm{~cm}$ beneath/above normal-polarity horizons (Table 1). The reverse-polarity field carried by the DRM should reflect a brief episode that occurred within quite a short time $(<5 \mathrm{~cm}$ thickness). For this depth, we calculated a composite ChRM of low- and high-temperature components.

The ChRM directions and virtual geomagnetic pole (VGP) latitudes clearly define polarity boundaries (Fig. 4a-c). The reverse-polarity zone below $415 \mathrm{~cm}$ is overlain by a mixed-polarity zone consisting of 28 
Table 1 Results of paleomagnetic analysis

\begin{tabular}{|c|c|c|c|c|c|c|c|c|c|}
\hline $\begin{array}{l}\text { Depth } \\
(\mathrm{cm})\end{array}$ & $\begin{array}{l}\text { Age } \\
(\mathrm{ka})\end{array}$ & $\begin{array}{l}\mathrm{T} 1 \\
\left({ }^{\circ} \mathrm{C}\right)\end{array}$ & $\begin{array}{l}\mathrm{T} 2 \\
\left({ }^{\circ} \mathrm{C}\right)\end{array}$ & No of steps & MAD & $\begin{array}{l}\text { Dec } \\
\left({ }^{\circ}\right)\end{array}$ & $\begin{array}{l}\text { Inc } \\
\left(^{\circ}\right)\end{array}$ & $\begin{array}{l}\text { VGP lat. } \\
\left(^{\circ}\right)\end{array}$ & $\begin{array}{l}\text { VGP lon. } \\
\left(^{\circ}\right)\end{array}$ \\
\hline 154.0 & 764.37 & 200 & 680 & 11 & 1.6 & 7.7 & 48.0 & 81.1 & -122.1 \\
\hline 166.5 & 764.69 & 250 & 650 & 11 & 4.1 & -7.5 & 55.6 & 83.8 & 29.8 \\
\hline 176.0 & 764.93 & 200 & 400 & 5 & 13.3 & -4.4 & -25.4 & 41.4 & -67.0 \\
\hline 197.0 & 765.55 & 200 & 560 & 9 & 7.1 & 51.1 & -64.3 & -4.7 & -109.0 \\
\hline 197.0 & 765.55 & 250 & 530 & 7 & 5.9 & 56.7 & -56.8 & 0.5 & -114.2 \\
\hline 204.5 & 765.77 & 200 & 650 & 12 & 6.8 & 144.1 & 2.5 & -40.6 & 157.9 \\
\hline 209.5 & 765.91 & 200 & 590 & 10 & 3.1 & 2.8 & 55.3 & 87.6 & 177.4 \\
\hline 212.0 & 765.98 & 200 & 590 & 10 & 5.6 & -4.1 & 46.9 & 82.2 & -44.7 \\
\hline 230.0 & 766.50 & 250 & 620 & 11 & 2.6 & -4.4 & 50.9 & 85.0 & -24.5 \\
\hline 247.0 & 767.99 & 200 & 590 & 10 & 3.9 & 0.5 & 54.5 & 89.6 & -160.4 \\
\hline 258.0 & 768.95 & 200 & 560 & 7 & 1.9 & -5.2 & 48.0 & 82.6 & -34.9 \\
\hline 271.0 & 770.09 & 350 & 620 & 8 & 2.9 & -5.7 & 49.7 & 83.4 & -24.3 \\
\hline 281.0 & 771.32 & 200 & 620 & 11 & 2.7 & 1.1 & 55.0 & 89.0 & 168.5 \\
\hline 290.0 & 772.48 & 450 & 680 & 8 & 6.4 & 18.5 & 32.5 & 66.1 & -120.8 \\
\hline 300.0 & 773.76 & 200 & 590 & 10 & 5.7 & -16.1 & 46.8 & 74.6 & -5.3 \\
\hline 304.0 & 774.28 & 300 & 620 & 9 & 3.1 & 7.2 & 43.1 & 78.3 & -106.5 \\
\hline 309.0 & 774.84 & 200 & 530 & 8 & 5.4 & -7.0 & 50.2 & 82.9 & -15.4 \\
\hline 314.0 & 775.32 & 200 & 560 & 9 & 5.4 & -10.1 & 50.7 & 80.8 & -3.0 \\
\hline 321.5 & 776.04 & 300 & 560 & 7 & 11.3 & 35.2 & 68.5 & 59.9 & 152.7 \\
\hline 326.5 & 776.52 & 300 & 530 & 6 & 12.1 & 9.6 & 41.6 & 76.1 & -112.1 \\
\hline 331.5 & 776.82 & 350 & 590 & 7 & 9.3 & 23.4 & 58.8 & 70.9 & 176.8 \\
\hline 332.0 & 776.84 & 250 & 560 & 8 & 8.9 & -2.0 & 40.4 & 77.9 & -63.8 \\
\hline 337.0 & 776.96 & 450 & 590 & 5 & 9.9 & 16.7 & 21.7 & 61.8 & -109.2 \\
\hline 342.0 & 777.09 & 200 & 560 & 9 & 7.2 & 184.0 & -61.2 & -82.1 & -50.5 \\
\hline 347.0 & 777.21 & 250 & 590 & 9 & 10.0 & 126.2 & -34.4 & -40.1 & -166.8 \\
\hline 350.0 & 777.29 & 350 & 590 & 7 & 11.8 & 25.0 & 34.8 & 62.8 & -133.4 \\
\hline 355.0 & 777.41 & 250 & 530 & 7 & 6.0 & -7.4 & 43.3 & 78.3 & -37.6 \\
\hline 357.5 & 777.47 & 250 & 650 & 8 & 6.9 & 160.1 & -1.6 & -51.1 & 140.2 \\
\hline 360.0 & 777.54 & 250 & 590 & 9 & 8.4 & 7.0 & 50.9 & 83.2 & -134.0 \\
\hline 362.5 & 777.60 & 250 & 530 & 7 & 6.8 & 16.6 & 56.5 & 76.4 & -176.1 \\
\hline 363.0 & 777.61 & 250 & 560 & 8 & 5.8 & -6.8 & 44.1 & 79.1 & -38.3 \\
\hline 368.0 & 777.74 & 250 & 590 & 9 & 10.2 & 9.2 & 45.9 & 79.0 & -120.5 \\
\hline 370.5 & 777.80 & 250 & 620 & 11 & 6.4 & 161.3 & -21.1 & -60.5 & 147.1 \\
\hline 373.0 & 777.86 & 200 & 590 & 10 & 5.6 & 160.1 & -28.1 & -63.1 & 154.0 \\
\hline 375.5 & 777.93 & 200 & 620 & 11 & 1.4 & 176.8 & -46.4 & -82.2 & 128.7 \\
\hline 379.5 & 778.03 & 200 & 590 & 10 & 5.7 & 0.2 & 45.0 & 81.5 & -73.8 \\
\hline 382.0 & 778.09 & 300 & 620 & 9 & 11.6 & 183.8 & -56.9 & -86.1 & -22.3 \\
\hline 384.5 & 778.15 & 200 & 680 & 13 & 2.6 & 167.0 & -57.6 & -79.1 & -141.8 \\
\hline 387.0 & 778.21 & 200 & 680 & 13 & 2.5 & 164.5 & -40.6 & -72.2 & 160.3 \\
\hline 389.5 & 778.27 & 300 & 530 & 6 & 7.7 & 164.1 & -37.2 & -71.8 & 149.0 \\
\hline 392.0 & 778.34 & 200 & 680 & 13 & 1.3 & 180.3 & -43.5 & -80.3 & 105.8 \\
\hline 394.5 & 778.40 & 200 & 680 & 13 & 1.3 & 178.3 & -49.2 & -84.8 & 124.0 \\
\hline 395.0 & 778.42 & 250 & 680 & 12 & 6.9 & 179.1 & -57.3 & -87.0 & -86.5 \\
\hline
\end{tabular}


Table 1 Results of paleomagnetic analysis (Continued)

\begin{tabular}{llllllllll}
\hline $\begin{array}{l}\text { Depth } \\
(\mathrm{cm})\end{array}$ & $\begin{array}{l}\text { Age } \\
(\mathrm{ka})\end{array}$ & $\begin{array}{l}\mathrm{T} 1 \\
\left({ }^{\circ} \mathrm{C}\right)\end{array}$ & $\begin{array}{l}\mathrm{T} 2 \\
\left({ }^{\circ} \mathrm{C}\right)\end{array}$ & & No of steps & MAD & $\begin{array}{l}\text { Dec } \\
\left({ }^{\circ}\right)\end{array}$ & $\begin{array}{l}\text { Inc } \\
\left({ }^{\circ}\right)\end{array}$ & $\begin{array}{l}\text { VGP lat. } \\
\left({ }^{\circ}\right)\end{array}$ \\
\hline 397.5 & 778.48 & 200 & 680 & 13 & 2.2 & 170.1 & -45.1 & -78.1 & $\begin{array}{l}\text { VGP lon. } \\
\left({ }^{\circ}\right)\end{array}$ \\
400.0 & 778.55 & 200 & 680 & 12 & 2.5 & 167.6 & -48.5 & -78.1 & 155.4 \\
402.5 & 778.61 & 200 & 680 & 12 & 1.3 & 175.1 & -43.7 & -79.6 & 132.7 \\
405.0 & 778.68 & 200 & 680 & 13 & 1.7 & 169.2 & -52.2 & -80.8 & -173.5 \\
406.0 & 778.71 & 250 & 680 & 12 & 1.7 & 176.5 & -52.1 & -86.3 & 159.7 \\
408.5 & 778.77 & 200 & 680 & 13 & 2.4 & 163.4 & -47.3 & -74.4 & 176.9 \\
411.0 & 778.84 & 300 & 530 & 6 & 9.8 & -88.3 & 71.3 & 29.3 & 67.4 \\
413.5 & 778.90 & 300 & 530 & 6 & 9.8 & -47.0 & 53.3 & 51.6 & 29.6 \\
416.0 & 778.97 & 300 & 560 & 7 & 4.1 & 198.4 & -45.7 & -72.4 & 39.0 \\
418.5 & 779.04 & 300 & 560 & 7 & 3.5 & 160.2 & -45.0 & -71.0 & 176.3 \\
\hline
\end{tabular}

$T 1, T 2$ Temperature ranges of thermal demagnetization data used for principal component analysis

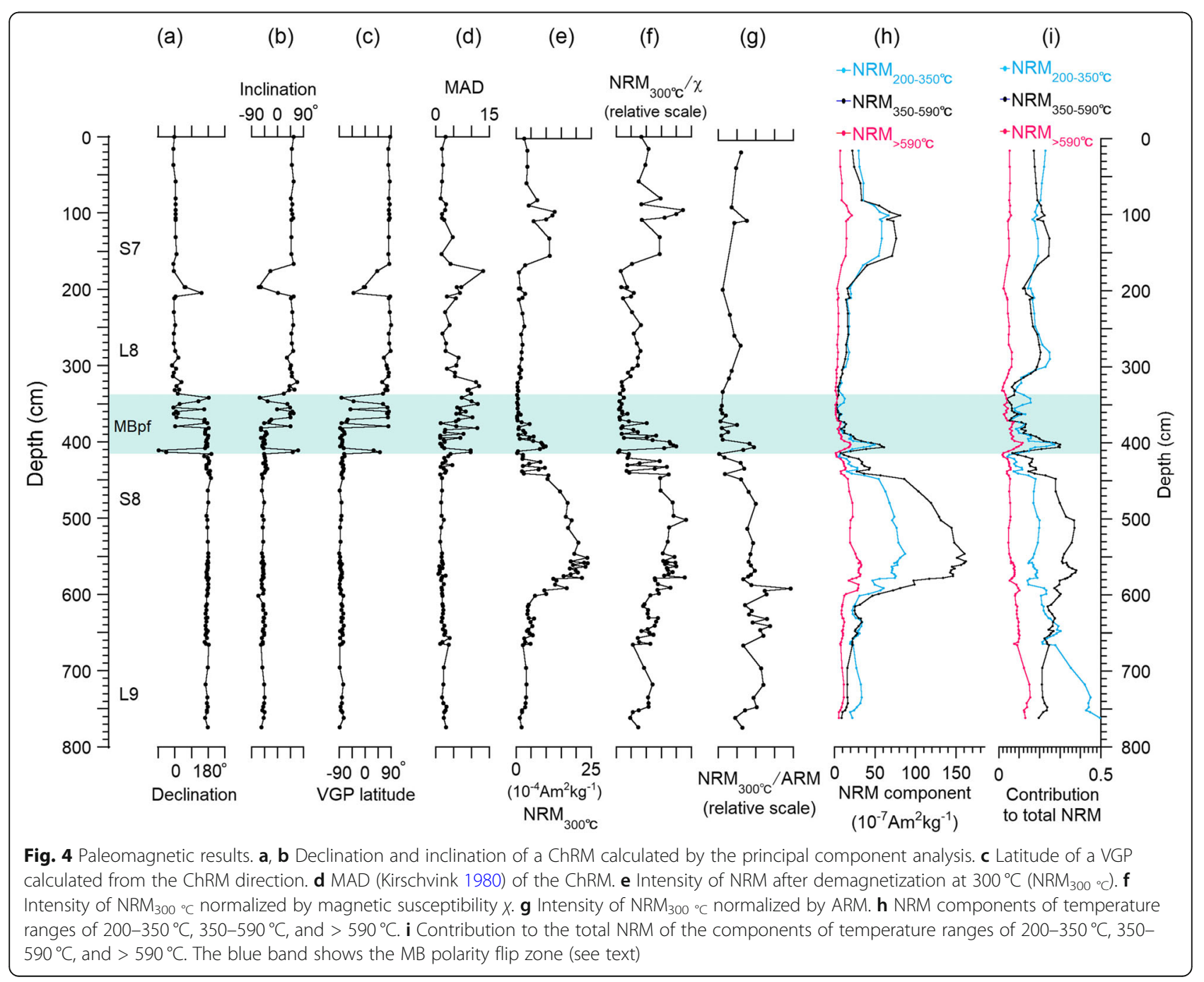


horizon data, which is further overlain by the normal-polarity zone above $341 \mathrm{~cm}$. The normal-polarity zone includes an excursion at $206-176 \mathrm{~cm}$ that consists of four excursional fields with VGP latitudes shallower than $45^{\circ}$. Throughout the section, the paleomagnetic directions are dominated by the full-normal/reverse-polarity directions. Except for those in the excursion, there are only two transitional directions, both within the polarity flip zone. The reverse- and normal-polarity zones correlate with the Matuyama and Brunhes chrons, respectively. The mixedpolarity zone includes nine polarity flips. Each polarity flip occurred within $2.5-5.0 \mathrm{~cm}$ of depth. Similar high numbers of rapid polarity changes have often been observed in high-resolution MB transition loess records (e.g., Yang et al. 2010; Jin and Liu 2011). We named the zone the "Matuyama-Brunhes polarity flip (MBpf) zone" (Ueno et al. 2019), which is the part of the MB transition that contains the low field intensity interval.

Six samples, from within the MBpf zone and just above it and within the excursion (Fig. 4d), had ChRMs with MAD values $>10$. They had quite low intensities of the NRMs demagnetized at $300{ }^{\circ} \mathrm{C}\left(\mathrm{NRM}_{300}{ }^{\circ} \mathrm{C}\right)$ and the normalized NRMs $\left(\mathrm{NRM}_{300}{ }^{\circ} \mathrm{C} X\right.$ and $\left.\mathrm{NRM}_{300}{ }^{\circ} \mathrm{C} / \mathrm{ARM}\right)$ (Fig. $4 \mathrm{~d}-\mathrm{g}$ ). Thus, the MAD values may reflect mainly the variability of field direction and partly the field intensity. The normalized NRM intensity curves may show that the upper ends of the curves do not reach the broad paleointensity peak spanning about 760-715 ka (Guyodo and Valet 1999).

High-resolution MB transition records from the CLP, including the present one, obtained by progressive THDs of samples collected at $2-3 \mathrm{~cm}$ depth intervals, have common features (Spassov et al. 2001; Wang et al. 2006; Jin and Liu 2010; Yang et al. 2010). All have a multiplepolarity flip zone and comprise paleomagnetic fields dominated by full-normal/reverse-polarity directions. On the other hand, there are differences between our record and those of others. The latter include more directions with VGP latitudes between $45^{\circ}$ and $-45^{\circ}$ and have larger MADs, which may be the result of errors due to smaller demagnetization steps used in ChRM calculations. Using data of only five steps (Spassov et al. 2001) or five steps/more than five steps (Yang et al. 2010) results in larger mean MAD values > 10 for the MBpf zone, values that are much larger than the value of 5.6 in this study. The polarity flip zone of each site differs in thickness (about 50-100 cm), with different numbers of flips (7 to 13); we do not include the top short episode that lies far $(25-50 \mathrm{~cm})$ above the MBpf zone in the Baoji and Xifeng sections (Yang et al. 2010). These differences would reflect dust accumulation rates, sampling intervals, and physical/chemical properties related to magnetization acquisition. As far as we can compare the present and previous high-resolution $\mathrm{MB}$ transition records, detailed stratigraphic correlations of short episodes between sites seem to be difficult. This may indicate centennial-scale variability in dust accumulation rates.

\section{Temperature components of NRM}

A viscous remanent magnetization (VRM) component was almost completely demagnetized at $200{ }^{\circ} \mathrm{C}$. We divided the NRM above $200^{\circ} \mathrm{C}$ into components between 200 and $350{ }^{\circ} \mathrm{C}\left(\mathrm{NRM}_{200-350}{ }^{\circ} \mathrm{C}\right)$, between 350 and $590{ }^{\circ} \mathrm{C}$ $\left(\mathrm{NRM}_{350-590}{ }^{\circ} \mathrm{C}\right)$, and above $590^{\circ} \mathrm{C}\left(\mathrm{NRM}_{>} 590{ }^{\circ} \mathrm{C}\right)$, which would be carried by magnetite + maghemite, magnetite, and hematite, respectively. For the S8 and S7 paleosol layers, all three components increase as $X$ increases. Thus, each component includes pedogenic components. However, except for the mature paleosol intervals, not all components match in variations; $\mathrm{NRM}_{200-350{ }^{\circ} \mathrm{C}}$ changes consistently with $\mathrm{NRM}>590{ }^{\circ} \mathrm{C}$ throughout and inconsistently with $\mathrm{NRM}_{350-590}{ }^{\circ} \mathrm{C}$ in part (Fig. $4 \mathrm{~h}, \mathrm{i}$ ). Therefore, again, the low-temperature magnetite-carrying component $\left(\mathrm{NRM}_{200-350}{ }^{\circ} \mathrm{C}\right)$ and the hematite-carrying component $\left(\mathrm{NRM}>590{ }^{\circ} \mathrm{C}\right)$ are probably dominated by DRM, whereas the middle-temperature magnetite-carrying component

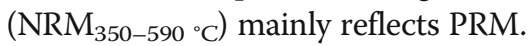

The vertical change in ARM shows a rapid increase above ca. $600-580 \mathrm{~cm}$, with a broad peak from $560-500$ $\mathrm{cm}$, followed by a gradual decrease until about $270 \mathrm{~cm}$ (Fig. 5a). Above $200 \mathrm{~cm}$, it repeats another increase/decrease that is relatively gradual. The NRM component < $200{ }^{\circ} \mathrm{C}\left(\mathrm{NRM}_{<200}{ }^{\circ} \mathrm{C}\right)$ is probably dominated by a VRM with the present field direction, carried by multi-domain (MD) magnetites. The $\mathrm{NRM}_{<200}{ }^{\circ} \mathrm{C}$, magnetic grain size proxy $(\mathrm{ARM} / X)$, and $X$ show a rapid increase at $600-580$ $\mathrm{cm}$, like the ARM (Fig. $5 \mathrm{a}-\mathrm{c}, \mathrm{e}$ ). Above $580 \mathrm{~cm}$ up to $440 \mathrm{~cm}$, the curves show complex changes. The NRM $<$ $200{ }^{\circ} \mathrm{C}$ has double peaks, correlated with the double peaks of the summer monsoon (SM) proxy $\chi_{\mathrm{FD}}$ (Fig. 5b, d). At these peaks, the magnetic grain size $(\mathrm{ARM} / \chi)$ has depressions that indicate an increase in coarse magnetite particles under strong pedogenesis. The TEM observation of a $1-10 \mu \mathrm{m}$ grain-size host silicate fraction revealed that Lingtai paleosol S8 samples included several-hundred-nanometer-long magnetite and 1-1.5 $\mu \mathrm{m}$ long hematite particles between layers of phyllosilicates (Hyodo et al. 2020). This TEM observation implies that authigenic magnetites could coarsen to MD-size and increase VRM at SM peaks. The median size, a winter monsoon (WM) proxy, and the $\mathrm{ARM} / X$ represent anti-phase changes with $\chi_{\mathrm{FD}}$ on the whole. However, the $\mathrm{ARM} / X$ and the median size represent different changes in the depth interval from about 440 to $330 \mathrm{~cm}$ (Fig. 5c, $\mathrm{f})$, where the grain size of silicates has been affected by WM strengthening related to an intensive increase of galactic cosmic rays (Ueno et al. 2019). For this interval, 
(a)

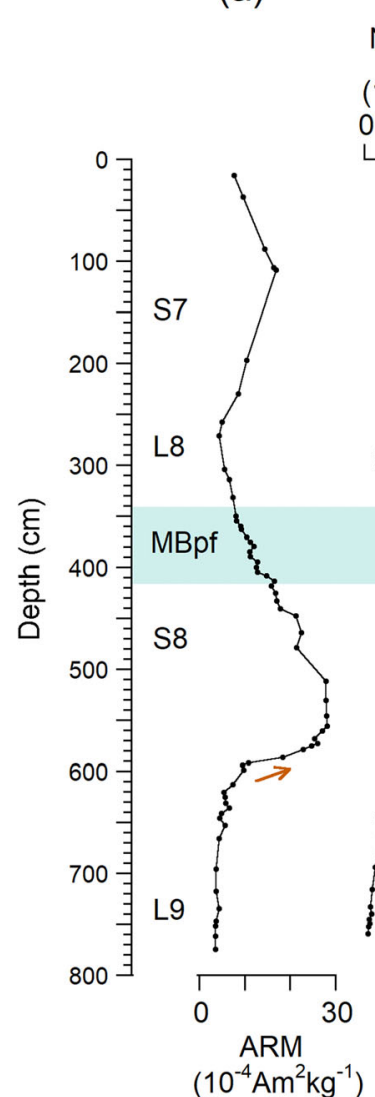

(b) $\mathrm{NRM}_{<200^{\circ} \mathrm{C}}$ (c) (d) $\left(10^{-7} \mathrm{Am}^{2} \mathrm{~kg}^{-1}\right)$

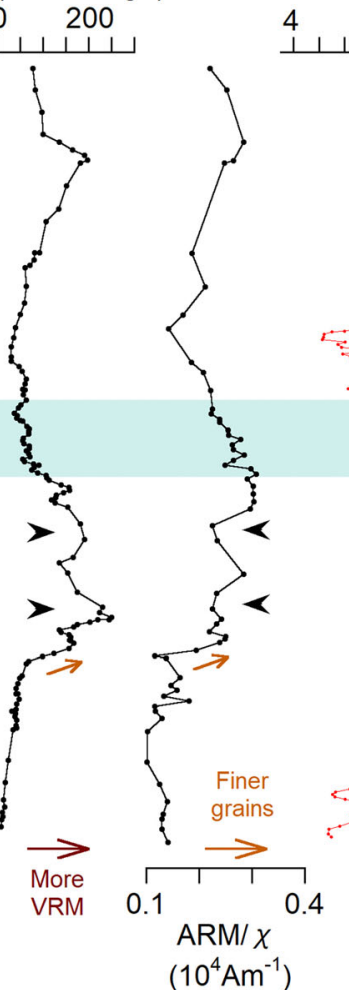

(d) $\quad$ (e)

(f)

\section{(1)} $\chi_{F D}(\%)$

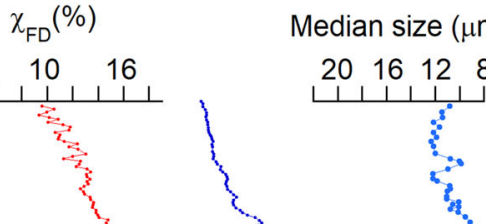

Median size $(\mu \mathrm{m})$ $\begin{array}{llll}20 & 16 & 12 & 8\end{array}$
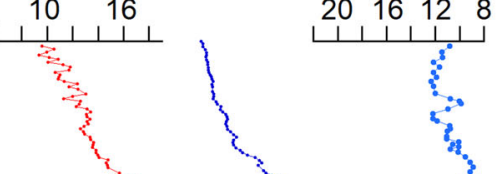

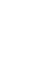

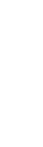




\section{Suborbital-scale climate-event stratigraphy-based age model}

Loess and paleosol layers are correlated with glacial and interglacial periods, respectively. The $X$ variation of a loess sequence, an East Asian SM proxy, is generally used for stratigraphic correlation with marine oxygen isotope data (Kukla 1987). The sequential correlation with MISs from the top to paleosol layer S6 (MIS 17) is consistent among studies. However, the correlations of layers from paleosol S7 to paleosol S8, within which lies the MB transition, differ. The MIS 19 interglacial period has generally been correlated with S7 (Ding et al. 2002; Sun et al. 2006; Hao et al. 2012) or S8 (Wang et al. 2006; Liu et al. 2008; Ueno et al. 2019). In consideration of the MB boundary lying in S8 or the S8-L8 transition, and between the sea-level highstand MIS 19.3 and lowstand MIS 19.2 (Bassinot et al. 1994; Ferretti et al. 2015; Hyodo and Kitaba 2015), the latter correlation seems more likely. In addition, the correlation of S7 with MIS 19 requires the assumption of extraordinarily large lockin depths of magnetization, e.g., a few to several meters. Such large lock-in depths are supported by neither the laboratory experiments (Wang and Løvlie 2010; Zhao and Roberts 2010) nor the loess records of the geomagnetic excursion and secular variation without significant downward shifts (Zhu et al. 1994; Heslop et al. 1999).

The East Asian SM and WM show inverse correlations in their orbital-scale changes; the SM strengthens and the WM weakens during interglacial periods, and vice versa during glacial periods (Kukla 1987; Maher 2016). In the high-resolution monsoon records of S7-L9 from Lingtai and Xifeng, even millennial-scale climate events exhibit anti-phase changes that are well correlated with MIS 19 Northern Hemisphere mid-latitude climate episodes (Ueno et al. 2019). In this study, we adopted an age model based on sequential correlation of more than 10 climate events, using the brief sea-level drop/cooling events observed in the Northwest Pacific and North Atlantic midlatitudes (Ueno et al. 2019). At present, this is the only age model with multiple suborbital-scale age constraints. The chronology for the original climatostratigraphy is based on orbital tuning with at least three age controls for the MIS 19 interval, related to MIS 20.0, MIS 19.2, and MIS 19.0 (Hyodo et al. 2017). The MIS 19.2 sea-level lowstand provides quite an important age constraint for the $\mathrm{MB}$ transition. The deep-sea benthic $\delta^{18} \mathrm{O}$ data are usually orbitally tuned with only the control point of MIS 20.0, and without the points of MIS 19.2 and even MIS 19.0 (based on the assumption of a constant accumulation rate), whose published astronomical ages can be revised to several thousand years older assuming the point of MIS 19.2 (Hyodo and Kitaba 2015).

The time variations of the Lingtai magnetic polarity, $\mathrm{SM}$, and WM proxies are plotted in Fig. $6 \mathrm{a}-\mathrm{c}$, where the age-control points are shown by the solid circle and the square symbols denoted " 1 to $10 \mathrm{~b}$ " defined in the core TB2 of the Chiba Section, central Japan, and the IODP Site U1313 core in the North Atlantic (Hyodo et al. 2017; Ueno et al. 2019). "x1 to $x 4$ " represent SM features defined in the Xifeng data (Ueno et al. 2019). For comparison, the high-resolution magnetic polarity stratigraphy and the paleoceanic/paleoclimate data are plotted in Fig. 6. In addition to the magnetic polarity stratigraphy (Hyodo et al. 2006), diatom-based sea-level proxies (Maegakiuchi et al. 2016) and pollen-based paleoclimate data (Kitaba et al. 2009, 2013, 2017), both from Osaka Bay, were obtained (Fig. 6d-g). The 10-year resolution biogenic productivity proxy record $(\mathrm{Ca} / \mathrm{Ti})$ from the TB2 core dominantly reflects the sea-level and water-temperature changes in the Northwest Pacific (Fig. 6h) (Hyodo et al. 2017). The planktonic oxygen isotope data of the core from IODP Site U1313 mainly reflect sea level, water temperature, and salinity. The age models for these datasets are based on orbital tuning using the ice-volume model (Fig. 6j) (Hyodo et al. 2017). The age controls used for the tuning include the MIS 19.2 sea-level lowstand, an important key point for the MB transition (Hyodo and Kitaba 2015). The depths of the Lingtai sequence were dated by linear interpolation between the control points and extrapolation beyond the uppermost and lowermost control points with the mean accumulation rates of the nearest intervals.

In the present age model, we assume an absence of large hiatuses in the loess sequence. The sequential correlation of millennial-scale climate events (Fig. 6) may support the assumption, although the correlation does not certify the absence of submillennial-scale hiatuses. A series of centennial-scale climate variations over the past 1000 years, including the Little Ice Age recorded in a loess sequence (Kang et al. 2018), indicates continuous dust deposition at a centennial scale. However, there is another case; the Laschamp geomagnetic excursion observed at many profiles in the CLP is absent in the profile near the Yellow River, which indicates either a hiatus or a large decrease in the dust accumulation rate (Zhu et al. 2007). Thus, we need to be careful when discussing centennial-scale events.

\section{Background climate for the MB transition}

Based on the quantitative climate estimate from pollen assemblage data (Kitaba et al. 2013), the climate of the early MIS 19 interglacial is characterized by a cooling event $(783-777 \mathrm{ka})$ intercalated by the warmest $(777-$ $775 \mathrm{ka})$ and a warm (786-783 ka) interval (Fig. 6). The climate signal corresponding to the warmest interval is observed at all of the sites: the SM maximum " $\mathrm{x} 3$ " and WM minimum at Lingtai and the warm events "G-H" in the Northwest Pacific and North Atlantic mid- 


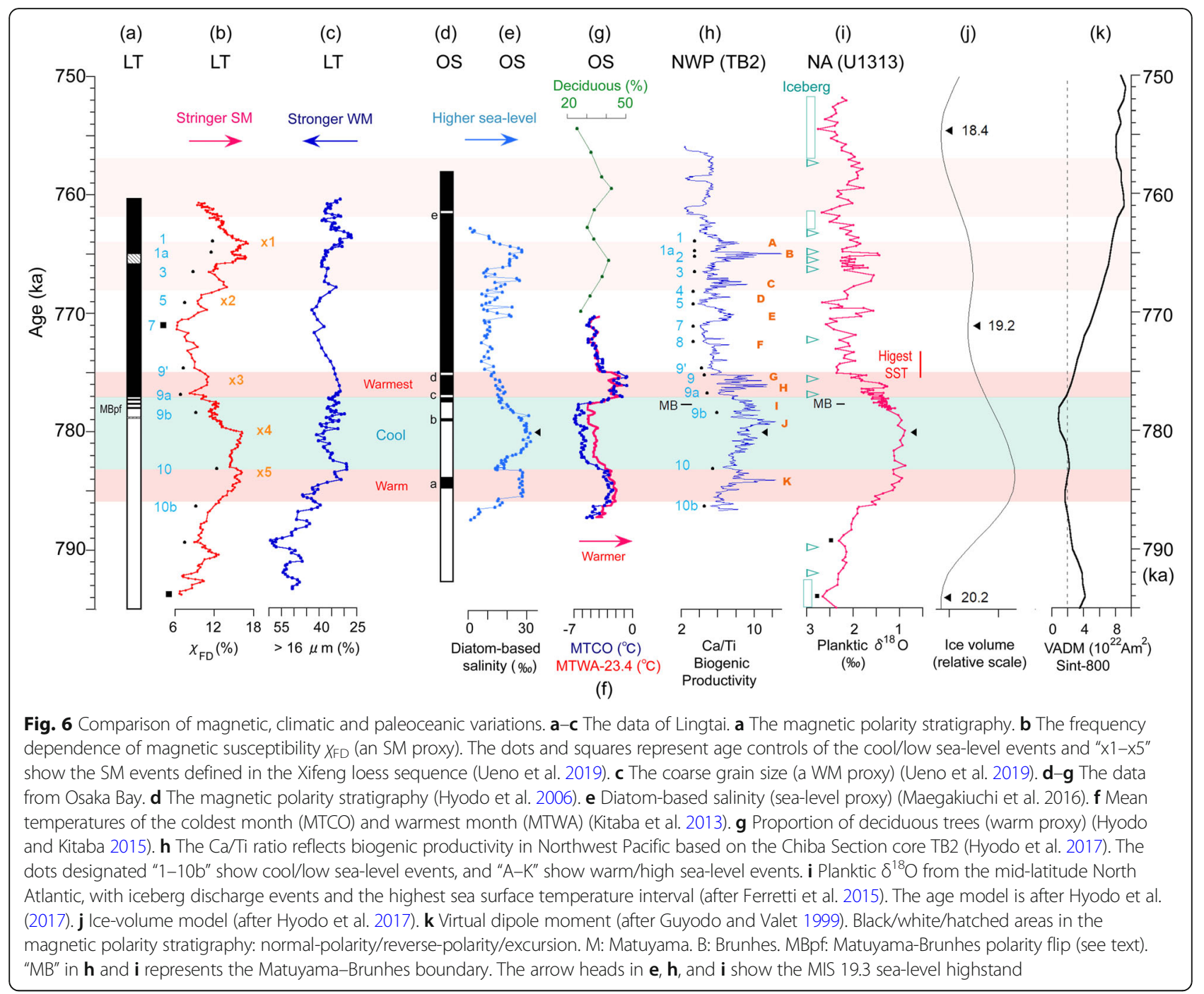

latitudes. In the North Atlantic mid-latitudes, the alkenone-based sea surface temperature (SST) values are highest within and just after the warmest interval (Ferretti et al. 2015). The cooling event that occurred during the low geomagnetic field interval, which has been interpreted as having been caused by increased galactic cosmic ray flux and low cloud cover (Kitaba et al. 2012, 2013, 2017), is observed in Lingtai (and Xifeng) as a WM intensification event due to the more highly cooled continent that resulted from an umbrella effect of low cloud (Fig. 6g) (Ueno et al. 2019). Around the sea-level highstand MIS 19.3 in the North Atlantic, the cooling event may have affected the flattened planktic $\delta^{18} \mathrm{O}$ curve and the $1-2{ }^{\circ} \mathrm{C}$ lower SST than in the warmest interval in the North Atlantic (Fig. 6i), and furthermore the much increased accumulation rate (see Fig. 5 of Hyodo and Kitaba 2015, and Fig. S10 of Hyodo et al. 2017). The relatively low-resolution pollen assemblage data after $770 \mathrm{ka}$ show a cool climate with no evergreen tree pollen, but the sum of deciduous broadleaved tree pollen (Fagus and Quercus (deciduous)) shows two relatively warm intervals at about 767-764 ka and $762-757 \mathrm{ka}$, respectively. The warm/high sea-level events " $A$ " to " $C$ " occurred during the former warm interval, and the latter warm-interval climate seems to be reflected in the paleoceanic data of the Northwest Pacific and North Atlantic mid-latitudes (Fig. 6h, i).

The MBpf zone, dated at about 779 to $777 \mathrm{ka}$, lies in the latest stage of the cooling event. It occurred during the weakest dipole field, which was $<1 / 4$ the present field (Fig. 6k). Therefore, the frequent magnetic polarity reversals are likely strongly related to the low geomagnetic field. The MBpf interval includes the main MB boundary reported from the Northwest Pacific and North Atlantic, within the warm event "I" (Fig. 6h, i). The MBpf interval may correlate with the interval from the base of short episode " $\mathrm{b}$ " to the top of episode "c" within event "I" in Osaka Bay (Fig. 6a, d). Episode "d" 
just after the warmest interval in Osaka Bay is absent in the Lingtai magnetic record, possibly due to resolutionrelated problems. The short episode observed just above the sharp peak of $X$ ("x3") in Xifeng (Yang et al. 2010), dated at about $775 \mathrm{ka}$ by the age model (Ueno et al. 2019), correlates well with episode "d" in Osaka Bay. The Lingtai sequence did not record an event comparable to episode "a" in the warm interval in Osaka Bay (Fig. 6d), which correlates well with the precursor to the MB reversal in the Luochuan loess sequence (Jin et al. 2012). The precursor in Luochuan is recorded in the flattened broad $X$ peak that is correlated to the SM peak " $x 5$ " in Lingtai. The absence of the precursor in the Lingtai loess sequence may be due to a hiatus or a slower accumulation rate, relative to that of the Luochuan sequence.

\section{Post-reversal geomagnetic excursion}

The geomagnetic excursion in paleosol S7, comprising only excursional fields with no full-reversal field (Figs. 3c and 4a), lies around warm event B and is dated at ca. $766 \mathrm{ka}$, with an interval of about $1 \mathrm{ka}$. This excursion can be correlated with neither episode "e" at about $762 \mathrm{ka}$ (Fig. 6d) nor the Stage 17 excursion ranging in depth from 356 to $352 \mathrm{~m}$ in the Osaka Bay $1700 \mathrm{~m}$ core (Biswas et al. 1999). The latter is dominated by full-reversal fields. According to the recent linear age model for the MIS 17 marine clay layer (Kitaba et al. 2013), the Stage 17 excursion ranges in age from 710 to $703 \mathrm{ka}$. The excursion in Lingtai is stratigraphically well correlated with the Baoji A excursion in the S7 paleosol layer (Yang et al. 2007), although the detailed data represent a complex field behavior that is frequently interrupted by normal-polarity intervals (Yang et al. 2010). The complex field behavior may be the result of the much higher resolution; the excursion comprises 23 data points at $2.2 \mathrm{~cm}$ intervals on average.

\section{Rapid polarity changes during the MB polarity flip zone} The polarity reversals are numbered $1-9$, as in the VGP path (Fig. 7). The age model shows that each occurred within 65 years $(2.5 \mathrm{~cm}$ sample spacing), except for no. 9, which occurred within ca. 130 years $(5 \mathrm{~cm}$ sample spacing). The span of each polarity zone ranges from 65 years for nos. $3-4 / 6-7$ to 800 years for nos. $2-3$. The minimum polarity intervals ( 65 years) consist of a single NRM record that comprises two components with almost antipodal directions for nos. 3-4 (Fig. 3i) and one component for nos. 6-7. These results imply that each full polarity reversal, and even a full round of polarity reversals, occurred within 65 years and that the DRM and PRM were acquired within a time difference $<65$ years, the limit for our 65 -year resolution paleomagnetic record.

Such rapid reversal may have been caused by the fields in the liquid outer core of the Earth. The field in the outer core may reverse on time scales < 500 years (Gubbins 1999). Polarity changes with few transitional directions have been observed often in high-accumulation rate and fine-grained sediments (e.g., Hyodo et al. 2006, 2011; Sagnotti et al. 2014). This will be discussed further later.

\section{VGP clusters and few low-latitude VGPs}

Our paleomagnetic data from Lingtai have only six excursional VGPs (lower than $45^{\circ}$ in latitude), four of which are in the excursion zone and two of which are adjacent to the polarity flip in the MBpf zone (Fig. 4). It is noted that the relatively low-latitude $\left(40-65^{\circ} \mathrm{S}\right)$ VGPs concentrate in the upper MBpf zone, all just before/after the polarity flip. In addition, they cluster in the SW Pacific region (Fig. 7), where MB transitional VGPs from lava flows of the Hawaiian and Canary Islands (Coe et al. 2004; Singer et al. 2005) and lacustrine deposits of Java (Hyodo et al. 2011) cluster. The results imply that these sites were dominated by dipolar fields with a pole located in the SW Pacific.

There is no low-latitude VGP in Lingtai. Few lowlatitude VGPs may be a feature of high-resolution polarity transition records of high-accumulation-rate fine-grained sediments; marine clays in Osaka Bay (accumulation rate; $60 \mathrm{~cm} / \mathrm{ka}$ ) (Hyodo et al. 2006) and lacustrine clays/silty clays in Java (the MB transition spans about $700 \mathrm{~cm}$ thick sequence) (Hyodo et al. 2011). Sediment records a timeaveraged geomagnetic field. The time represented by the sample thickness is a minimum duration for averaging, and it lengthens in DRM due to gradual post-depositional compaction depending on the sediment materials (Hyodo 1984; Hyodo et al. 1993). The time for a $2 \mathrm{~cm}$ thick sample in the present study is estimated to be about 50 years based on our age model. An averaging time of fields significantly longer than 50 years is implausible in this study because the data resolved rapid polarity reversals within 65 years and the multi-component NRM adjacent to a polarity reversal did not span two horizons ( $5 \mathrm{~cm} / 130$ years). As mentioned above, small lock-in depths/time for loess are also supported by laboratory experiments (Wang and Løvlie 2010; Zhao and Roberts 2010) and the $X$ values of modern soils (Maher and Thompson 1995; Balsam et al. 2011; Yang et al. 2015; Kang et al. 2018).

There may be transitional fields with low-latitude VGPs, as shown by the data from the Canary Islands (Fig. 7b). However, they were probably short in persistence time and/or weak in strength and so easily averaged out in sediment magnetization. Under the dominant dipolar fields (Fig. 7b), slow accumulation rates and/or thick lock-in zone sediments can have magnetizations of VGPs with various latitudes, including low latitudes, forged by the vector sum of two wide-angle direction components with various ratios. Thus, the presence or 

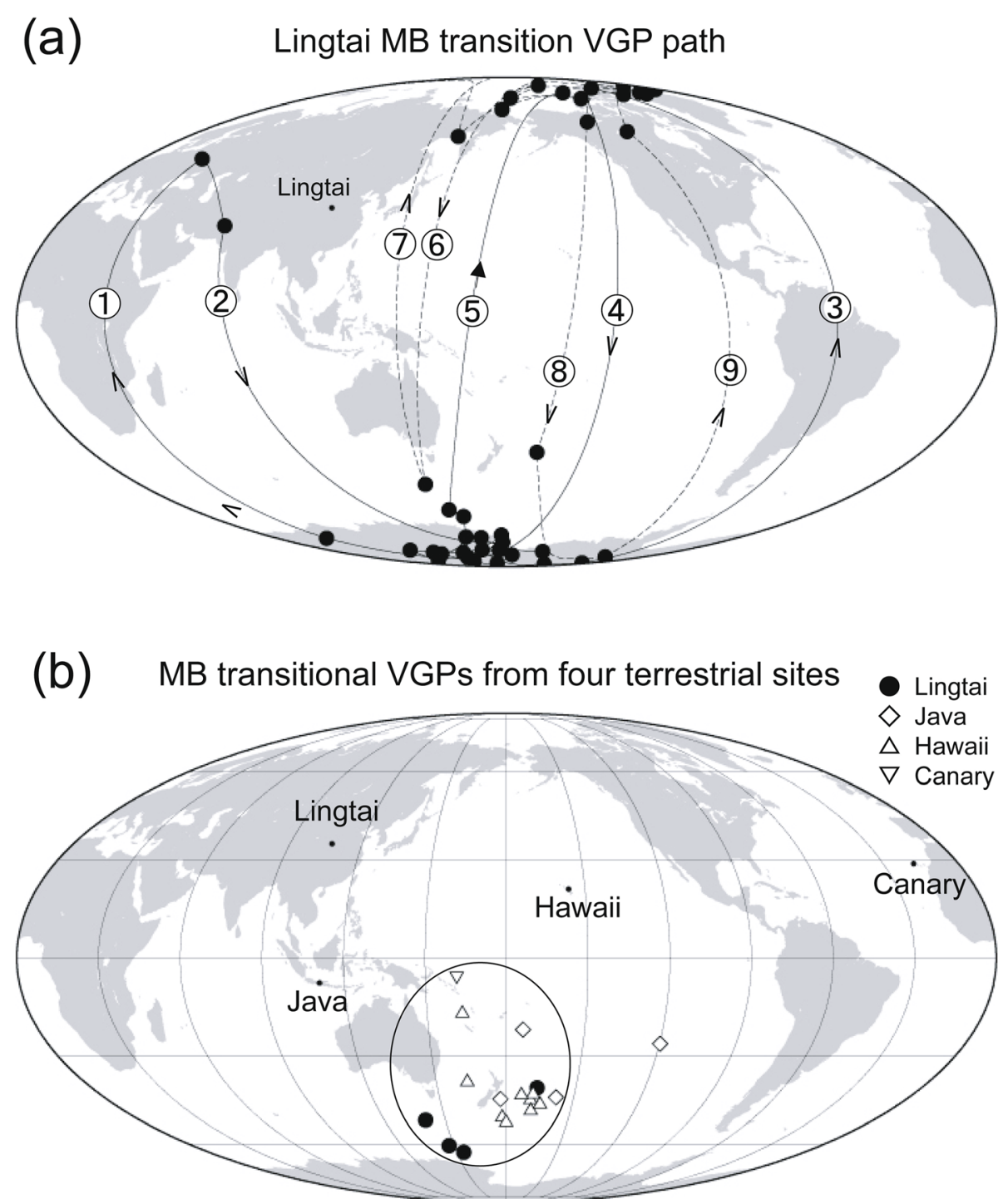

Fig. 7 The Matuyama-Brunhes (MB) transition VGPs. a The VGP pass during the MB polarity flip zone. The polarity changes are numbered 1-9. The pass after no. 5 polarity change is shown by broken lines. $\mathbf{b}$ The MB transitional VGPs clustered in the southwest Pacific from the four terrestrial sites of Lingtai (this study), Java (Hyodo et al. 2011), and the Hawaii and Canary Islands (Coe et al. 2004; Singer et al. 2005)

absence of low-latitude VGPs can be used as a criterion to assess the fidelity and resolution of transition records determined by the accumulation rate and lock-in zone of a sediment.

\section{MB transition stratigraphy from loess and lacustrine and lava sequences}

The age of the MB reversal has been discussed by combining the radiometric dates of lavas and the astronomical ages of deep-sea sediments (e.g., Channell et al. 2010; Singer et al. 2019). However, researchers have never discussed the stratigraphic position of the radiometrically dated lavas' MB transition fields in the sediment record of the MB transition, which spans several thousand years. Here, we discuss the stratigraphic position of the MB transitional fields of Hawaiian lavas (Coe et al. 2004; Singer et al. 2005) in comparison with the MB transition stratigraphy records.

The horizon mean paleomagnetic directions from lacustrine clays of Java reveal the MB transition over about a $700 \mathrm{~cm}$ thick sequence characterized by few low-latitude VGPs (Hyodo et al. 2011) (Fig. 8b). There are only four reverse-polarity low-latitude VGPs that cluster in the South Pacific. Thermoremanent magnetizations of lava flows in the Haleakala section of Maui Island, Hawaii, yield snapshot fields of the MB transition (Coe et al. 2004). A vertical plot of the VGP latitude against flow unit numbers shows a succession of nine 


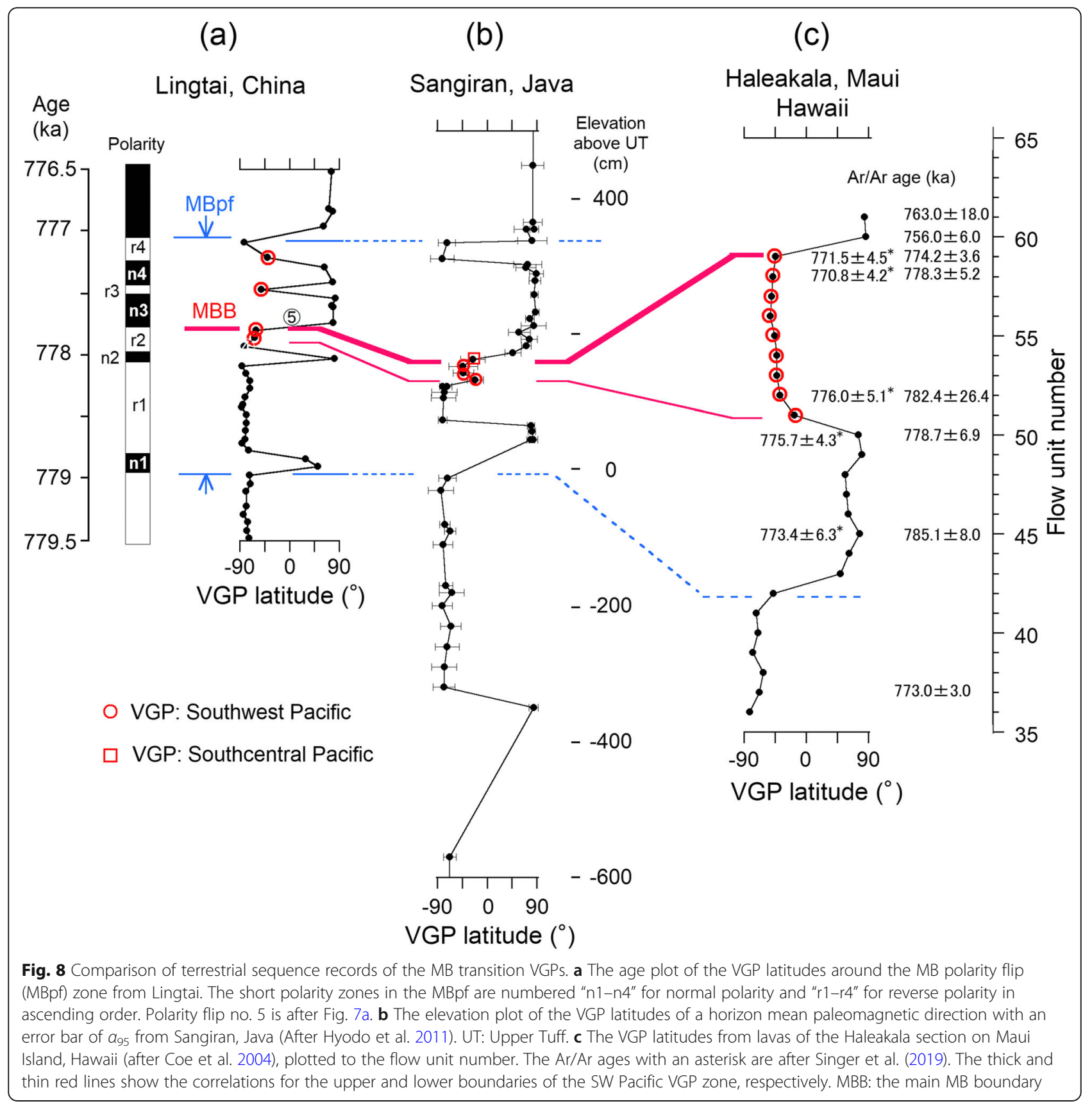

lava flows with almost the same VGP located in the SW Pacific just above the short normal-polarity interval (Fig. 8c). At Lingtai, the no. 5 polarity reversal is underlain by two successive horizons of the SW Pacific VGP (over $5 \mathrm{~cm} / 130$ years), above which two isolated horizons also show the SW Pacific VGP (Fig. 8a). In Java, the SW Pacific VGPs are concentrated in three successive horizons from 133 to $153 \mathrm{~cm}$ in elevation. In Hawaii, as mentioned above, the SW Pacific VGPs are concentrated in nine successive lava flow units. Thus, it is reasonable to correlate these successive SW Pacific VGP intervals among Lingtai, Java, and Hawaii (Fig. 8).
Centennial-scale magnetic polarity stratigraphy is defined for the Lingtai sequence as in Fig. 8a, where the polarity zones are numbered " $\mathrm{n} 1-\mathrm{n} 4$ " for normal polarity and "r1-r4" for reverse polarity in ascending order. We propose correlating the beginning of the MBpf to the polarity change at $0 \mathrm{~cm}$ elevation (the base of the upper tuff (UT)) and the end to the polarity change at $336 \mathrm{~cm}$ elevation in Java. In this correlation model, the short polarity zone $\mathrm{r} 3$ is absent in the Java sequence, possibly due to the large sample intervals $(10 \mathrm{~cm})$ or filtering out by a magnetization lock-in zone. The correlation provides an average accumulation rate of about 
$170 \mathrm{~cm} / \mathrm{ka}$ for the Java sequence. The SW Pacific VGP interval is estimated to be about 120 years in Java, which is consistent with the estimate of about 130 years for Lingtai. Based on these estimates, the nine MB transitional Hawaiian lavas would have erupted within a period of 120-130 years, in the late stage of warm event "I".

We also propose defining the main MB boundary at the no. 5 reverse-to-normal polarity change (the $\mathrm{r} 2 / \mathrm{n} 3$ boundary) (Fig. 8a), because the time spans of normalpolarity intervals subsequently become longer than those of reverse-polarity intervals, as proposed in the Osaka Bay core (Hyodo et al. 2006). Consequently, radiometric dating of the $\mathrm{MB}$ transitionally magnetized lavas of Hawaii becomes important for the chronostratigraphy of the Early to Middle Pleistocene transition as well as the geomagnetic polarity timescale. Our age model estimate, ca. $777.8-777.9 \mathrm{ka}$, for the SW Pacific VGP interval is mostly consistent within errors for the reported $\mathrm{Ar} / \mathrm{Ar}$ dates ranging from $770.8 \pm 4.2$ to $782.42 \pm 6.4 \mathrm{ka}$ (Coe et al. 2004; Singer et al. 2019) and the weighted mean age of $776 \pm 2 \mathrm{ka}$ (Singer et al. 2005). The short normalpolarity zones $\mathrm{n} 1 / \mathrm{n} 2$ and the short reverse-polarity zones $\mathrm{r} 3 / \mathrm{r} 4$ can be regarded as parts of the precursor and rebound episodes of the main MB reversal, respectively (Valet et al. 2012).

\section{Conclusion}

We performed detailed magnetic analyses of the loesspaleosol sequence at Lingtai in the CLP with centennialresolution climatostratigraphy correlated with paleoceanic events in the Northwest Pacific and North Atlantic midlatitudes. Our chronology is based on orbital tuning with control points, including the sea-level lowstand MIS 19.2, an important anchor point for the MB transition chronology. Based on the results, we drew the following conclusions. (1) The pedogenic magnetite-carrying remanent magnetization was mostly acquired within $2.5 \mathrm{~cm}$ below the acquisition depth of DRM. (2) The thickness of the lock-in zone of both DRM and PRM in the loess does not exceed $5 \mathrm{~cm}$ and is most probably $<2.5 \mathrm{~cm}$. (3) The $\mathrm{MB}$ transition terminated with the multiple-polarity flip zone coinciding with the lowest dipole strength. The polarity flip zone, dated at 779-777 ka and tentatively named the MBpf zone, began between the warm events "I" and "J" and terminated with the end of the cooling event. (4) Most of the polarity flips during the MBpf zone occurred within $2.5 \mathrm{~cm}$ (65 years), i.e., they did not occur over two successive horizons $(5.0 \mathrm{~cm} / 130$ years). (5) Four VGPs adjacent to a polarity flip in the upper part of the MBpf zone cluster in the SW Pacific, where MB transitional VGPs from lavas of the Hawaiian and Canary Islands and lacustrine deposits of Java also cluster. These sites would have been governed by dipolar fields in the late MBpf interval. (6) The SW Pacific VGP zone probably spans $120-130$ years in Lingtai and Java and is a useful key bed for MB transition stratigraphy. The reverse-to-normal polarity reversal dated at $778 \mathrm{ka}$ at Lingtai occurs at the upper end of the SW Pacific VGP zone in Java and Hawaii, as well as in Lingtai. The reversal is a good candidate for the main $\mathrm{MB}$ boundary. (7) We found an excursion that occurred during warm event $\mathrm{B}$, which is dated at about $766 \mathrm{ka}$ and spanned about $1 \mathrm{ka}$.

\section{Abbreviations \\ MB: Matuyama-Brunhes; VGP: Virtual geomagnetic pole; MIS: Marine isotope stage; CLP: Chinese Loess Plateau; NRM: Natural remanent magnetization; $x$ : Low field magnetic susceptibility; AMS: Anisotropy of low-field magnetic susceptibility; ARM: Anhysteretic remanent magnetization; AF: Alternating field; DC: Direct current; IRM: Isothermal remanent magnetization; FORC: First-order reversal curve; Bcr: Remanent coercive force; SD: Single domain; SP: Superparamagnetic; $B_{1 / 2}$ : The field at which half of the saturation IRM is reached; PSD: Pseudo-single domain; Hc: Magnetic coercivity; ChRM: Characteristic remanent magnetization; THD: Thermal \\ demagnetization; MAD: Maximum angular deviation; DRM: Detrital remanent magnetization; PRM: Remanent magnetization carried by pedogenic magnetic particles; MBpf: Matuyama-Brunhes polarity flip; VRM: Viscous remanent magnetization; MD: Multi-domain; $X_{F D}$ : Frequency dependence of magnetic susceptibility; SM: Summer monsoon; WM: Winter monsoon; IODP: Integrated Ocean Drilling Program; MTWA: Mean temperature of the warmest month; MTCO: Mean temperature of the coldest month; SST: Sea surface temperature}

\section{Acknowledgements}

Part of this study was performed in collaboration with the Center for Advanced Marine Core Research, Kochi University (reference numbers: 12A002, 13A011, 14A023, and 15A001) and with the support of JAMSTEC. We thank M. Tobi and K. Takasaki for fieldwork. Constructive comments from Hounslow and an anonymous reviewer helped to improve the paper.

\section{Authors' contributions}

$\mathrm{MH}$ designed the study and wrote the paper. $\mathrm{KB}, \mathrm{MH}, \mathrm{YY}$, and $\mathrm{MS}$ conducted the experiments, and MH, TY, and SK made the field works. JF, MM, and BB contributed to the discussion, and all contributed to editing the paper. All authors read and approved the final manuscript.

\section{Funding}

This study was supported by grant numbers 19340151, 20654043, 26610162, and $18 \mathrm{H} 03609$ from the Japanese Society for the Promotion of Science.

\section{Availability of data and materials}

Requests for materials should be addressed to Masayuki Hyodo (e-mail: mhyodo@kobe-u.ac.jp).

\section{Competing interests}

The authors declare that they have no competing interests.

\section{Author details}

${ }^{1}$ Research Center for Inland Seas, Kobe University, Kobe 657-8501, Japan. ${ }^{2}$ Department of Planetology, Kobe University, Kobe 657-8501, Japan. ${ }^{3}$ School of Earth Sciences and Resources, China University of Geosciences, Beijing 100083, China. ${ }^{4}$ Museum of Nature and Human Activities, Hyogo, Sanda 669-1546, Japan. ${ }^{5}$ School of Ocean Sciences, China University of Geosciences, Beijing 100083, China. ${ }^{6}$ Institute of Seismology and Volcanology, Hokkaido University, Sapporo 060-0810, Japan. ${ }^{7}$ Department of Physics, EPS, University of Burgos, Burgos 09006, Spain.

Received: 31 October 2019 Accepted: 19 May 2020

Published online: 17 June 2020

\section{References}

Balsam WL, Ellwood BB, Ji J, Williams ER, Long X, El Hassani A (2011) Magnetic susceptibility as a proxy for rainfall: worldwide data from tropical and temperate climate. Quat Sci Rev 30:2732-2744 
Bassinot FC, Labeyrie LD, Vincent E, Quidelleur X, Shackleton NJ, Lancelot Y (1994) The astronomical theory of climate and the age of the BrunhesMatuyama magnetic reversal. Earth Planet Sci Lett 126:91-108

Biswas DK, Hyodo M, Taniguchi Y, Kaneko M, Katoh S, Sato H, Kinugasa Y, Mizuno K (1999) Magnetostratigraphy of Plio-Pleistocene sediments in a 1700-m core from Osaka Bay, southwestern Japan and short geomagnetic events in the middle Matuyama and early Brunhes chrons. Palaeogeogr Palaeoclimatol Palaeoecol 148:233-248

Channell JET, Kleiven HF (2000) Geomagnetic palaeointensities and astrochronological ages for the Matuyama-Brunhes boundary and the boundaries of the Jaramillo Subchron: palaeomagnetic and oxygen isotope records from ODP Site 983. Philos Trans Royal Soc A 358:1027-1047

Channell JET, Hodell DA, Singer BS, Xuan C (2010) Reconciling astrochronological and ${ }^{40} \mathrm{Ar} /{ }^{39} \mathrm{Ar}$ ages for the Matuyama-Brunhes boundary and late Matuyama Chron. Geochem Geophys Geosyst 11:Q0AA12. doi:https://doi.org/10.1029/ 2010GC003203

Coe RS, Singer BS, Pringle MS, Zhao X (2004) Matuyama-Brunhes reversal and Kamikatsura event on Maui. Earth Planet Sci Lett 222:667-684

deMenocal PB, Ruddiman WF, Kent DV (1990) Depth of post-depositional remanence acquisition in deep-sea sediments: a case study of the Brunhes-Matuyama reversal and oxygen isotope Stage 19.1. Earth Planet Sci Lett 99:1-13

Ding ZL, Derbyshire E, Yang SL, Yu ZW, Xiong SF, Liu TS (2002) Stacked 2.6-Ma grain size record from the Chinese loess based on five sections and correlation with the deep-sea $\delta^{18} \mathrm{O}$ record. Paleoceanography 17:1033. https://doi.org/10.1029/2001PA000725

Ferretti P, Crowhurst SJ, Naafs BDA, Barbante C (2015) The Marine Isotope Stage 19 in the mid-latitude North Atlantic Ocean: astronomical signature and intra-interglacial variability. Quat Sci Rev 108:95-110

Gubbins D (1999) The distinction between geomagnetic excursions and reversals. Geophys J Int 137:F1-F3

Guyodo Y, Valet JP (1999) Global changes in intensity of the Earth's magnetic field during the past $800 \mathrm{kyr}$ (Sint-800). Nature 399:249-252

Hao Q, Wang L, Oldfield F, Peng S, Qin L, Song Y, Xu B, Qiao Y, Bloemendal J, Guo Z (2012) Delayed build-up of Arctic ice sheets during 400,000-year minima in insolation variability. Nature 490:393-396

Harrison RJ, Feinberg JM (2008) FORCinel: an improved algorithm for calculating first-order reversal curve distributions using locally weighted regression smoothing. Geochem Geophys Geosyst 9:Q05016. https://doi.org/10.1029/ 2008GC001987

Heider F, Zitzelsberger A, Fabian K (1996) Magnetic susceptibility and remanent coercive force in grown magnetite crystals from $0.1 \mu \mathrm{m}$ to $6 \mathrm{~mm}$. Phys Earth Planet Inter 93:239-256

Heslop D, Shaw J, Bloemendal J, Chen F, Wang J, Parker E (1999) Sub-millennial scale variations in East Asian monsoon systems recorded by dust deposits from the northwestern Chinese Loess Plateau. Phys Chem Earth 24:785-792. https://doi.org/10.1016/S1464-1895(99)00115-5

Heslop D, Dekkers MJ, Kruiver PP, van Oorschot IHM (2002) Analysis of isothermal remanent magnetization acquisition curves using the expectationmaximization algorithm. Geophys J Int 148:58-64

Hyodo M (1984) Possibility of reconstruction of the past geomagnetic field from homogeneous sediments. J Geomag Geoelectr 36:45-62

Hyodo M, Kitaba I (2015) Timing of the Matuyama-Brunhes geomagnetic reversal: Decoupled thermal maximum and sea-level highstand during Marine Isotope Stage 19. Quat Int 383:136-144

Hyodo M, Itota C, Yaskawa K (1993) Geomagnetic secular variation reconstructed from wide-diameter cores of Holocene sediments in Japan. J Geomag Geoelectr 45:669-696

Hyodo M, Biswas DK, Noda T, Tomioka N, Mishima T, Itota C, Sato H (2006) Millennial to submillennial-scale features of the Matuyama-Brunhes geomagnetic polarity transition from Osaka Bay, southwestern Japan. J Geophys Res 111:B02103. https://doi.org/10.1029/2004JB003584

Hyodo M, Matsu'ura S, Kamishima Y, Kondo M, Takeshita Y, Kitaba I, Danhara T, Aziz F, Kurniawan I, Kumai H (2011) High-resolution record of the MatuyamaBrunhes transition constrains the age of Javanese Homo erectus in the Sangiran dome, Indonesia. Proc Natl Acad Sci USA 108(49):19563-19568. https://doi.org/10.1073/pnas.1113106108

Hyodo M, Bradák B, Okada M, Katoh S, Kitaba I, Dettman DL, Hayashi H, Kumazawa K, Hirose K, Kazaoka O, Shikoku K, Kitamura A (2017) Millennialscale northern Hemisphere Atlantic-Pacific climate teleconnections in the earliest Middle Pleistocene. Sci Rep 7:10036
Hyodo M, Sano T, Matsumoto M, Seto Y, Suzuki K, Bradák B, Fukuda J, Shi M, Yang T (2020) Nano-sized authigenic magnetite and hematite particles in mature-paleosol phyllosilicates: New evidence for a magnetic enhancement mechanism in the loess sequences of China. J Geophys Res 125: e2019JB018705. https://doi.org/10.1029/2019JB018705

Jin C, Liu Q (2010) Reliability of the natural remanent magnetization recorded in Chinese loess. J Geophys Res 115:B04103 https://doi.org/10.1029/2009JB006703

Jin C, Liu Q (2011) Revisiting the stratigraphic position of the Matuyama-Brunhes geomagnetic polarity boundary in Chinese loess. Palaeogeogr Palaeoclimatol Palaeoecol 299:309-317

Jin S, Liu S, Larrasoaña JC (2012) A precursor to the Matuyama-Brunhes reversal in Chinese loess and its palaeomagnetic and stratigraphic significance. Geophys J Int 190:829-842

Kang S, Wang X, Roberts HM, Duller GAT, Cheng P, Lu Y, An Z (2018) Late Holocene anti-phase change in the East Asian summer and winter monsoons. Quat Sci Rev 188:28-36

Kirschvink JL (1980) The least-squares line and plane and the analysis of palaeomagnetic data. Geophys J R Astr Soc 62:699-718

Kitaba I, Iwabe C, Hyodo M, Katoh S, Matsushita M (2009) High-resolution climate stratigraphy across the Matuyama-Brunhes transition from palynological data of Osaka Bay sediments in southwestern Japan. Palaeogeogr Palaeoclimatol Palaeoecol 272:115-123

Kitaba I, Hyodo M, Katoh S, Matsushita M (2012) Phase-lagged warming and the disruption of climatic rhythms during Matuyama-Brunhes magnetic polarity transition. Gondwana Res 21:595-600. https://doi.org/10.1016/j.gr.2011.07.005

Kitaba I, Hyodo M, Katoh S, Dettman DL, Sato H (2013) Mid-latitude cooling caused by geomagnetic field minimum during polarity reversal. Proc Natl Acad Sci USA 110:1215-1220. https://doi.org/10.1073/pnas.1213389110

Kitaba I, Hyodo M, Nakagawa T, Katoh S, Dettman DL, Sato H (2017) Geological support for the Umbrella Effect as a link between geomagnetic field and climate. Sci Rep 7:40682

Kukla G (1987) Loess stratigraphy in central China. Quat Sci Rev 6:191-219

Liu Q, Banerjee SK, Jackson MJ, Chen F, Pan Y, Zhu R (2003) An integrated study of the grain-size-dependent magnetic mineralogy of the Chinese loess/ paleosol and its environmental significance. J Geophys Res 108(B9):2437 https://doi.org/10.1029/2002JB002264

Liu Q, Jackson MJ, Banerjee SK, Maher BA, Deng C, Pan Y, Zhu R (2004) Mechanism of the magnetic susceptibility enhancements of the Chinese loess. J Geophys Res 109:B12107 https://doi.org/10.1029/2004JB003429

Liu Q, Roberts AP, Rohling EJ, Zhu R, Sun Y (2008) Post-depositional remanent magnetization lock-in and the location of the Matuyama-Brunhes geomagnetic reversal boundary in marine and Chinese loess sequences. Earth Planet Sci Lett 275:102-110

Maegakiuch K, Hyodo M, Kitaba I, Hirose K, Katoh S, Sato H (2016) Brief sea-level fall event and centennial to millennial sea-level variations during Marine Isotope Stage 19 in Osaka Bay, Japan. J Quat Sci 31:809-822

Maher BA (2016) Palaeoclimatic records of the loess/palaeosol sequences of the Chinese Loess Plateau. Quat Sci Rev 154:23-84. https://doi.org/10.1016/j. quascirev.2016.08.004

Maher BA, Thompson R (1995) Paleorainfall reconstructions from pedogenic magnetic susceptibility variations in the Chinese loess and paleosols. Quat Res 44:383-391

Okada M, Suganuma Y, Haneda Y, Kazaoka O (2017) Paleomagnetic direction and paleointensity variations during the Matuyama-Brunhes polarity transition from a marine succession in the Chiba composite section of the Boso Peninsula, central Japan. Earth Planets Space 69:45. https://doi.org/10.1186/s40623-017-0627-1

Pike CR, Roberts AP, Verosub KL (1999) Characterizing interactions in fine magnetic particle systems using first order reversal curves. J Appl Phys 85: 6660-6667

Pike CR, Roberts AP, Verosub KL (2001) FORC diagrams and thermal relaxation effects in magnetic particles. Geophys J Int 145:721-730

Porter SC, An Z (1995) Correlation between climate events in the North Atlantic and China during the last glaciation. Nature 375:305-308

Roberts AP, Cui YL, Verosub KL (1995) Wasp-waisted hysteresis loops: Mineral magnetic characteristics and discrimination of components in mixed magnetic systems. J Geophys Res 100:17909-17924

Roberts AP, Pike CR, Verosub KL (2000) First-order reversal curve diagrams: a new tool for characterizing the magnetic properties of natural samples. J Geophys Res 105:28461-28475

Roberts AP, Almeida TP, Church NS, Harrison RJ, Heslop D, Li Y, Li J, Muxworthy AR, Williams W, Zhao X (2017) Resolving the origin of pseudo-single domain 
magnetic behavior. J Geophys Res 122:9534-9558 https://doi.org/10.1002/ 2017JB014860

Sagnotti L, Scardia G, Giaccio B, Liddicoat JC, Nomade S, Renne PR, Sprain CJ (2014) Extremely rapid directional change during Matuyama-Brunhes geomagnetic polarity reversal. Geophys J Int 199:1110-1124

Singer BS, Hoffman KA, Coe RS, Brown LL, Jicha BR, Pringle MS, Chauvin A (2005) Structural and temporal requirements for geomagnetic field reversal deduced from lava flows. Nature 434:633-636 https://doi.org/10.1038/ nature03431

Singer BS, Jicha BR, Mochizuki N, Coe RS (2019) Synchronizing volcanic, sedimentary, and ice core records of Earth's last magnetic polarity reversal. Sci Adv 5:eaaw4621

Spassov S, Heller F, Evans ME, Yue LP, Ding ZL (2001) The Matuyama/Brunhes geomagnetic polarity transition at Lingtai and Baoji, Chinese loess plateau. Phys Chem Earth A 26:899-904

Spassov S, Heller F, Kretzschmar R, Evans ME, Yue LP, Nourgaliev DK (2003) Detrital and pedogenic magnetic mineral phases in the loess/palaeosol sequence at Lingtai (Central Chinese Loess Plateau). Phys Earth Planet Inter 140:255-275

Suganuma Y, Yokoyama Y, Yamazaki T, Kawamura K, Horng CS, Matsuzaki H (2010) ${ }^{10} \mathrm{Be}$ evidence for delayed acquisition of remanent magnetization in marine sediments: Implication for a new age for the Matuyama-Brunhes boundary. Earth Planet Sci Lett 296:443-450

Sun YB, Clemens SC, An ZS, Yu ZW (2006) Astronomical timescale and palaeoclimatic implication of stacked 3.6-Myr monsoon records from the Chinese Loess Plateau. Quat Sci Rev 25:33-48

Ueno Y, Hyodo M, Yang T, Katoh S (2019) Intensified East Asian winter monsoon during the last geomagnetic reversal transition. Sci Rep 9:9389

Valet JP, Fournier A, Courtillot V, Herrero-Bervera E (2012) Dynamical similarity of geomagnetic field reversals. Nature 490:89-93

van Velzen AJ, Dekkers MJ (1999) Low-temperature oxidation of magnetite in loess-paleosol sequences: a correction of rock magnetic parameters. Stud Geophys Geod 43:357-375

van Velzen AJ, Zijderveld JDA (1995) Effects of weathering on single-domain magnetite in Early Pliocene marine marls. Geophys J Int 121:267-278

Wang R, Løvlie R (2010) Subaerial and subaqueous deposition of loess: experimental assessment of detrital remanent magnetization in Chinese loess. Earth Planet Sci Lett 298:394-404

Wang Y, Cheng H, Edwards RL, He Y, Kong XG, An Z, Wu JY, Kelly MJ, Dykoski CA, Li XD (2005) The Holocene Asian monsoon: links to solar changes and North Atlantic climate. Science 308:854-857

Wang X, Yang Z, Løvlie R, Sun Z, Pei J (2006) A magnetostratigraphic reassessment of correlation between Chinese loess and marine oxygen isotope records over the last 1.1 Ma. Phys Earth Planet Inter 159:109-117

Yang T, Hyodo M, Yang ZN, Fu JL (2004) Evidence for the Kamikatsura and Santa Rosa excursions recorded in eolian deposits from the southern Chinese Loess Plateau. J Geophys Res 109:B12105. https://doi.org/10.1029/ 2004JB002966

Yang T, Hyodo M, Yang ZN, Fu JL (2007) Two geomagnetic excursions during the Brunhes chron recorded in Chinese loess-palaeosol sediments. Geophys J Int 171:104-114. https://doi.org/10.1111/j.1365-246X.2007.03522.x

Yang T, Hyodo M, Yang Z, Ding L, Li H, Fu J, Wang S, Wang H, Mishima T (2008) Latest Olduvai short-lived reversal episodes recorded in Chinese loess. J Geophys Res 113:B05103. https://doi.org/10.1029/2007JB005264

Yang T, Hyodo M, Yang Z, Li H, Maeda M (2010) Multiple rapid polarity swings during the Matuyama-Brunhes transition from two high-resolution loesspaleosol records. J Geophys Res 115:B05101. https://doi.org/10.1029/ 2009JB006301

Yang S, Ding Z, Li YY, Wang X, Jiang WY, Huang XF (2015) Warming-induced northwestward migration of the East Asian monsoon rain belt from the Last Glacial Maximum to the mid-Holocene. Proc Natl Acad Sci USA 112:13178-13183

Zhao X, Roberts AP (2010) How does Chinese loess become magnetized? Earth Planet Sci Lett 292:112-122

Zhu RX, Zhou LP, Laj C, Mazaud A, Ding ZL (1994) The Blake geomagnetic polarity episode recorded in Chinese loess. Geophys Res Lett 21:697-700

Zhu RX, Zhang R, Deng CL, Pan YX, Liu QS, Sun YB (2007) Are Chinese loess deposits essentially continuous? Geophys. Res. Lett. 34:L17306. https://doi. org/10.1029/2007GL030591

\section{Publisher's Note}

Springer Nature remains neutral with regard to jurisdictional claims in published maps and institutional affiliations.

\section{Submit your manuscript to a SpringerOpen ${ }^{\circ}$ journal and benefit from:}

- Convenient online submission

- Rigorous peer review

- Open access: articles freely available online

- High visibility within the field

- Retaining the copyright to your article

Submit your next manuscript at $\boldsymbol{\nabla}$ springeropen.com 